\title{
Improving Anaerobic Digestion of Wheat Straw by Plasma-Assisted Pretreatment
}

\author{
Stefan Heiske, ${ }^{1}$ Nadja Schultz-Jensen, ${ }^{1,2}$ Frank Leipold, ${ }^{3}$ and Jens Ejbye Schmidt ${ }^{1,4}$ \\ ${ }^{1}$ Department of Chemical and Biochemical Engineering, Technical University of Denmark, 2800 Lyngby, Denmark \\ ${ }^{2}$ Department of Geochemistry, Geological Survey of Denmark and Greenland (GEUS), Øster Voldgade, 1327 Copenhagen K, Denmark \\ ${ }^{3}$ Department of Physics, Technical University of Denmark, 2800 Lyngby, Denmark \\ ${ }^{4}$ Masdar Institute, P.O. Box 54224, Abu Dhabi, United Arab Emirates \\ Correspondence should be addressed to Stefan Heiske; shei@kt.dtu.dk
}

Received 12 February 2013; Accepted 27 March 2013

Academic Editor: Jayr de Amorim Filho

Copyright (c) 2013 Stefan Heiske et al. This is an open access article distributed under the Creative Commons Attribution License, which permits unrestricted use, distribution, and reproduction in any medium, provided the original work is properly cited.

\begin{abstract}
Plasma-assisted pretreatment (PAP) of lignocellulosic biomass has been shown to be an efficient method to decompose lignin and consequently facilitate microbial access to cellulose and hemicellulose. In the present study, PAP was tested for its suitability to enhance bioconversion of wheat straw to methane. In thermophilic batch experiments, methane yields of up to $366 \mathrm{~mL} / \mathrm{g}$ volatile solids (VSs) were achieved, accounting for a yield increase of $45 \%$. Common lignin-derived inhibitors like 5-hydroxymethylfurfural (5-HMF) and furfural were not detected after PAP, but toxicity test resulted in lower methane yields at higher substrate concentrations, indicating the presence of other unidentified inhibitors. However, in a continuous lab-scale biogas reactor experiment, stable codigestion of cattle manure with 20\% PAP wheat straw was demonstrated, while no signs of adverse effects on the anaerobic digestion process were observed. After the introduction of the pretreated wheat straw to the reactor, volatile fatty acid concentrations remained low and stable, while gas production increased. In co-digestion, the PAP wheat straw was converted at an average yield of $343 \mathrm{~mL} \mathrm{CH}_{4} / \mathrm{gVS}$.
\end{abstract}

\section{Introduction}

Anaerobic digestion (AD) is a widely applied method of managing agricultural byproducts such as animal manure and crop residues with multiple benefits. Treating organic material in biogas plants can produce renewable energy in the form of biogas, reduce land-use related environmental impacts, and improve the fertilizer quality of manure. These benefits have increased the interest in biogas technology worldwide. At present, the economic benefits of $\mathrm{AD}$ of agricultural residues are, however, limited because manure has a low energy density and many fibrous residues are only poorly degraded. This results in a low biogas yield which is a barrier to the expansion of biogas technology for energy production purposes. However, manure and crop residues hold the potential for a more efficient conversion to biogas as a considerable fraction of the organic material remains undigested in currently applied biogas processes.
The main reason for the low yields lies in the structure of the biomass. Crop residues and fibers contained in manure mainly consist of lignocellulose, which is poorly degraded in biogas reactors as lignin is not degradable under anaerobic conditions and prevents microbial access to cellulose and hemicelluloses $[1,2]$. Hence, removing lignin can facilitate anaerobic degradation of the fibers and thereby increase the biogas yield of manure and crop residues significantly.

Various pretreatment methods aiming at the destruction of the fiber structures or the removal of lignin have been investigated. The majority of these studies are related to the improvement of sugar release, for example, ethanol production [3, 4]. However, a number of studies have investigated pretreatment methods that specifically aim to increase the methane yield of recalcitrant biomass. Size reduction (maceration) of manure fibers led to an increase of $25 \%$ [5]. Also, $23 \%$ and $30 \%$ improvement was achieved with chemical and biological treatment of manure, respectively 


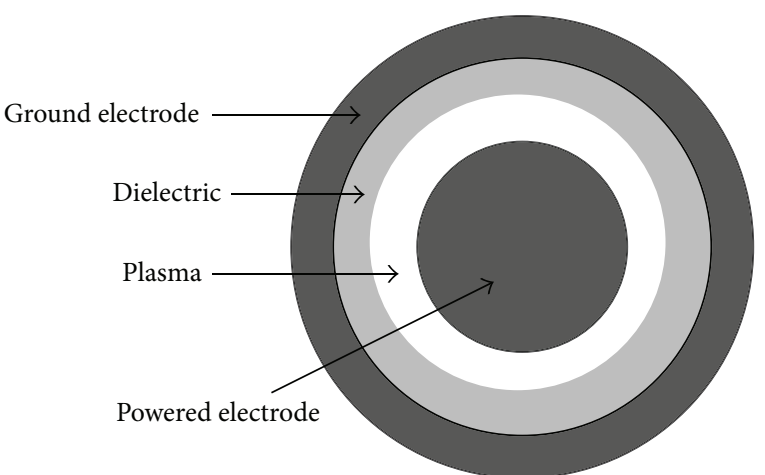

FIGURE 1: Schematic drawing of the dielectric barrier charge (front view). Electrodes (dark gray), dielectric barrier (gray), and plasma volume (white).

[6]. Thermal pretreatment of the solid fraction of manure was reported to improve the yield by $9 \%-24 \%$ [7]. Extrusion applied on straw and the solid fraction of manure resulted in $70 \%$ and $27 \%$ increases, respectively [8]. Up to $40 \%$ more methane was exploited from biowaste by applying thermal wet oxidation [9]. However, many pretreatment methods have disadvantages such as low efficiency, the addition of chemicals, or the formation of compounds that inhibit subsequent digestion. Moreover, the energy consumption is often too high when compared to the energy gained by the pretreatment.

Few studies have tested plasma to assist the pretreatment of biomass. The potential of using cold plasma at atmospheric pressure and ambient temperature for the pretreatment of wheat straw has been described by Vidal [10]. The reagent in such a process is ozone which is produced from air or pure oxygen in the plasma. Ozone is predicted to degrade unsaturated organic compounds in lignin, whereas saturated compounds such as carbohydrates are degraded only to a minor extent [11]. Experiments with PAP of wheat straw carried out by Schultz-Jensen et al. [12, 13] indicated an efficient and selective degradation of lignin, confirming Vidal's findings. These studies suggest PAP to be a potentially suitable and promising method for the treatment of crop residues and manure fibers prior to $\mathrm{AD}$. However, the effect of PAP on the biogas process and the methane yield of wheat straw has not been investigated yet and is the focus of this study.

The PAP method applied in this study follows the method established by Schultz-Jensen et al. [13], using the same custom-made lab-scale reactor employed in Schultz-Jensen's previous works. In addition, a modified reactor was used for PAP, which featured three separate layers of wheat straw with different treatment intensities. The treated biomass was analyzed for lignin concentration and available sugars. The effect of the PAP on the methane potential of wheat straw was investigated in batch trials. Furthermore, we tested long-term performance of an $\mathrm{AD}$ process fed with a substrate mixture of manure and PAP wheat straw in a continuous biogas reactor experiment.

\section{Materials and Methods}

2.1. Substrate. The wheat straw (Triticum aestivum L.) was grown and harvested after a drying period in Denmark during summer 2008. The straw was baled into $500 \mathrm{~kg}$ bales and stored at ambient temperature.

2.2. Ozone Generation by means of Plasma. The $\mathrm{O}_{3}$ was generated by means of a dielectric barrier discharge (DBD) operating at atmospheric pressure and ambient temperature. The electrodes were coaxially arranged and separated by an $\mathrm{Al}_{2} \mathrm{O}_{3}$ cylinder serving as a dielectric barrier (Figure 1). The design is based on the DBD used in [14]. Typical waveforms for voltage, current, and spectra from optical emission for pulsed DBDs can be found in [15]. The discharge was powered by $\mathrm{AC}$ voltage pulses. One pulse consisted of three full sinusoidal periods. The period time was set to $54 \mu \mathrm{s}$. The average power delivered to the DBD could be varied by varying the time between two pulses and was indicated by the power supply. The operation gas of the DBD was oxygen enriched air $\left(40 \% \mathrm{O}_{2}, 60 \% \mathrm{~N}_{2}\right)$ at a flow of 12 standard liters per minute (SLM). The power was adjusted to $230 \mathrm{~W}$.

The relevant reactions for generating ozone in a DBD are given in reactions (1)-(4) (later). The oxygen molecule is dissociated by electron impact (reactions (1) and (2)). The output products are $\mathrm{O}\left({ }^{1} \mathrm{D}\right)$ and $\mathrm{O}\left({ }^{3} \mathrm{P}\right)$ [16]. As described by Penetrante [17], reaction (1) is dominant in this type of discharge. The oxygen atom reacts with an oxygen molecule to ozone (reactions (3) and (4)). Reactions (3) and (4) are three body reactions where $\mathrm{M}$ is $\mathrm{O}_{2}$ or $\mathrm{N}_{2}$. Consider

$$
\begin{array}{r}
\mathrm{e}+\mathrm{O}_{2} \longrightarrow \mathrm{e}+\mathrm{O}\left({ }^{1} \mathrm{D}\right)+\mathrm{O}\left({ }^{3} \mathrm{P}\right) \\
\mathrm{e}+\mathrm{O}_{2} \longrightarrow \mathrm{e}+\mathrm{O}\left({ }^{3} \mathrm{P}\right)+\mathrm{O}\left({ }^{3} \mathrm{P}\right) \\
\mathrm{O}_{2}+\mathrm{O}\left({ }^{1} \mathrm{D}\right)+\mathrm{M} \longrightarrow \mathrm{O}_{3}+\mathrm{M} \\
\mathrm{O}_{2}+\mathrm{O}\left({ }^{3} \mathrm{P}\right)+\mathrm{M} \longrightarrow \mathrm{O}_{3}+\mathrm{M}
\end{array}
$$

2.3. The Pretreatment Reactor. The core of the reactor was a stainless steel sieve (Retsch test sieves, Retsch $\mathrm{GmbH}$, Germany) with a mesh size of $0.2 \mathrm{~mm}$ carrying the wheat straw (single layer reactor). The sieve has a diameter of $30 \mathrm{~cm}$ corresponding to an area of $706 \mathrm{~cm}^{2} . \mathrm{O}_{3}$ containing gas was forced through the sieve from the bottom. The exhaust gas was collected from the top for analysis.

The $\mathrm{O}_{3}$ concentration in the intake and exhaust was detected by means of ultraviolet absorption spectroscopy. A mercury lamp served as light source and a UV-photo diode in combination with an interference filter served as detector. The transmission maximum of the filter is at $254 \mathrm{~nm}$ where $\mathrm{O}_{3}$ has an absorption maximum. The ozone measurement technique is detailed in [18]. Depending on the pretreatment progress, the $\mathrm{O}_{3}$ concentration in the exhaust gas varied. The difference between the supplied $\mathrm{O}_{3}$ and the $\mathrm{O}_{3}$ in the exhaust was a measure of the $\mathrm{O}_{3}$ consumption of the straw. A more detailed description of the pretreatment process can be found in [12].

Additionally, a modified version of the described pretreatment reactor was used in this study, which contained 
a core of three vertically cascaded stainless steel sieves in exchange to just one stainless steel sieve. This setup allowed accounting for different treatment intensities, as $\mathrm{O}_{3}$ penetrated through the biomass via bottom, mid, and top layer successively while gradually being consumed. In the following, this modified version is referred to as multiplelayer reactor and its layers are labeled as BOT, MID, and TOP (bottom, middle and top layer, resp.). The original setup without separate layers is referred to as single-layer reactor (SIN). Apart from the layers, both reactor types had identical technical features which have previously been described [13].

2.4. Pretreatment. The wheat straw was milled to a final particle size of $1 \mathrm{~mm}$ using a technical mill (MF 10 basic, IKA-Werke GmbH \& Co. KG, Germany). After milling, water was added to the wheat straw to obtain a dry matter content of $45 \%$. Particle size and dry matter content were chosen according to the method established by Schultz-Jensen et al. $[12,13]$. The PAP was applied at atmospheric pressure for $1 \mathrm{~h}$. The concentration of $\mathrm{O}_{3}$ was $0.6 \%-1 \%$ at a gas flow rate of 12 SLM into the reactor. Mass loss by pretreatment was neglected as it was found to be below $1 \%$ after $1 \mathrm{~h}$ of treatment [12].

2.5. Determination of Methane Potentials. Methane potentials were determined for raw and pretreated samples in batch trials. Pretreated wheat straw was tested separately for material from the top, mid, and bottom layers (multiplelayer reactor) as well as from the treatment in the single layer reactor. Triplicates of each sample were distributed in $116 \mathrm{~mL}$ serum bottles in amounts of $0.4 \mathrm{~g}$ substrate (except for bottom layer where $0.2,0.4$, and $0.8 \mathrm{~g}$ substrates were used, corresponding to substrate concentrations of 5,10 , and $20 \mathrm{gVS} / \mathrm{L}$, resp.). The bottles were inoculated with $20 \mathrm{~g}$ of digestate (inoculum), taken from a lab-scale reactor treating cattle manure ( $4 \%$ VS) at a temperature of $53^{\circ} \mathrm{C}$. Water was added to each bottle to reach a total volume of $40 \mathrm{~mL}$. For subtraction of methane produced by the inoculum, vials only containing $20 \mathrm{~g}$ of inoculum were also made. All bottles were flushed with a gas mixture of $\mathrm{N}_{2} / \mathrm{CO}_{2}(80 \% / 20 \%)$, to obtain anaerobic conditions, closed with butyl rubber stoppers and aluminium crimps and incubated at $53^{\circ} \mathrm{C}$ for a period of 63 days. Methane production in the bottle headspace was measured by gas chromatography at increasing intervals, starting with 2 measurements a week during the first 15 days of incubation.

\subsection{Codigestion of Pretreated Wheat Straw and Cattle Manure} in a Lab-Scale Reactor. A 4.5-liter continuously stirred tank reactor (CSTR) with a working volume of 3.0 liter was run for a period of 167 days. The reactor was inoculated with effluent from a thermophilic $\left(55^{\circ} \mathrm{C}\right)$ full scale biogas plant (Snertinge, Denmark) which treats cattle/pig manure (80\%) and industrial waste $(20 \%)$. The reactor was operated at $53^{\circ} \mathrm{C}$ with a hydraulic retention time (HRT) of approximately 15 days. Stirring was done by a top-mounted propeller at intervals of 5 minutes for 45 seconds at $100 \mathrm{rpm}$. Substrate was automatically supplied by a peristaltic pump three times a day in loads of app. $66 \mathrm{~mL}$. The substrate initially consisted of cattle manure (ca. $4 \% \mathrm{VS}$ ) and accounted for an average organic loading rate (OLR) of $2.5 \mathrm{gVS} \mathrm{L}^{-1} \mathrm{~d}^{-1}$. After a startup phase, the reactor was run for 40 days to establish a stable digestion process and to ensure steady state conditions. In the following period (referred to days 0-59), the reactor was run under unchanged conditions. Data obtained during this period served as a reference for comparison with the following feed change. On day 60, the OLR was increased to $3.0 \mathrm{gVS} \mathrm{L}^{-1} \mathrm{~d}^{-1}$ by feeding a mixture of ozone-pretreated wheat straw from the single layer treatment and cattle manure. In this period, the fraction of added straw accounted for $20 \%$ of the OLR. The process was run for further 67 days, with otherwise unchanged process parameters. The performance of the digestion process in the reactor was monitored by total gas production, methane concentration and yield, $\mathrm{pH}$, and the concentration of volatile fatty acids (VFAs). The methane yield of the pretreated wheat straw was estimated as the average of the entire codigestion period by relating the sum of additionally produced methane (compared to the average methane production from the digestion of manure alone) to the total amount of added straw.

\subsection{Analysis}

2.7.1. Monitoring of Anaerobic Digestion Trials. Total solids (TSs) and VS were determined using standard methods [19]. The accumulating $\mathrm{CH}_{4}$ production in the batch flasks was measured by gas chromatography using flame ionization detection (Hewlett and Packard 6890 GC system). The total gas production of the reactor was measured by an automated metering system based on the principle of liquid displacement [20]. $\mathrm{CH}_{4}$ and $\mathrm{CO}_{2}$ concentrations in the produced biogas were determined by gas chromatography using a Mikrolab ML GC 82 with thermal conductivity detection (Mikrolab, Århus, Denmark). Biogas and methane production is given in norm liters (at $273 \mathrm{~K}$ and $1013 \mathrm{mbar}$ ). For VFA determination, $1 \mathrm{~mL}$ samples were acidified with $3 \mathrm{M}$ sulphuric acid, centrifuged at $4000 \mathrm{rpm}$ for $20 \mathrm{~min}$, and analyzed on HP 6890 GC system equipped with flame ionization detector.

2.7.2. Strong Acid Hydrolysis. The composition of the raw and pretreated wheat straw was measured by strong acid hydrolysis of the carbohydrates. Dried and milled samples $(160 \mathrm{mg})$ were treated with $72 \%(\mathrm{w} / \mathrm{w}) \mathrm{H}_{2} \mathrm{SO}_{4}(1.5 \mathrm{~mL})$ at $30^{\circ} \mathrm{C}$ for $1 \mathrm{~h}$. The solutions were diluted with $42 \mathrm{~mL}$ water and autoclaved at $121^{\circ} \mathrm{C}$ for $1 \mathrm{~h}$. The hydrolysates were filtered, and the Klason lignin content was determined as the weight of the insoluble residue minus the ash content. The recovery of $\mathrm{D}$-glucose, $\mathrm{D}$ xylose, and L-arabinose was determined by standard addition of sugars to the samples before autoclaving. The sugars were determined after separation on an high-performance liquid chromatography (HPLC) system (Shimadzu) with an Aminex HPX-87H column (BioRAD) at $63^{\circ} \mathrm{C}$ using $4 \mathrm{mM}$ $\mathrm{H}_{2} \mathrm{SO}_{4}$ as eluent and a flow rate of $0.6 \mathrm{~mL} / \mathrm{min}$; detection was done by a refractive index detector [21]. The samples were centrifuged with approximately 4,000 rpm for $10 \mathrm{~min}$. 
TABLE 1: Methane yields, lignin content, and concentration of available sugars of raw and PAP wheat straw.

\begin{tabular}{lccccc}
\hline Treatment (layer) & Series name & VS load $(\mathrm{gVS} / \mathrm{L})$ & ${\text { Yield }\left(\mathrm{mL} \mathrm{CH}_{4} / \mathrm{gVS}\right)}$ & ${\text { Lignin }(\% \text { of TS })^{1}}^{\left.\text {Total sugars }_{(\%} \text { of TS }\right)^{2}}$ \\
\hline Raw material & RAW & 10 & $254.04 \pm 19.49$ & 20.0 & 7.0 \\
Single layer & SIN & 10 & $317.04 \pm 19.49$ & 16.2 & 14.56 \\
Top layer & TOP & 10 & $286.05 \pm 7.35$ & 17.5 & 8.78 \\
Mid layer & MID & 10 & $300.97 \pm 0.09$ & 13 & 16.93 \\
Bottom layer (low load) & BOT5 & 5 & $366.46 \pm 9.36$ & 7.2 & 28.43 \\
Bottom layer (medium load) & BOT10 & 10 & $311.58 \pm 10.45$ & 7.2 & 28.43 \\
Bottom layer (high load) & BOT20 & 20 & $277.96 \pm 8.59$ & 7.2 & 28.43 \\
\hline
\end{tabular}

${ }^{1}$ Strong acid hydrolysis; ${ }^{2}$ enzymatic hydrolysis.

The supernatant was analyzed for glucose, xylose, arabinose, and acetic acid by HPLC as described earlier.

2.7.3. Inhibitor Analysis. The pretreated wheat straw was washed in order to extract lignin degradation products. The obtained washing water was analyzed for phenols by gas chromatography (GC). The concentrations of furans were measured using high-performance liquid chromatography (HPLC). Washing procedure, GC, and HPLC analysis are described in detail in [12].

\section{Results and Discussion}

3.1. Lignin Removal and Sugar Availability. Untreated wheat straw (RAW) contained $20.0 \%$ lignin and $7.0 \%$ of total sugars (Table 1). The straw treated in the single layer reactor had reduced lignin concentration (16.2\%) and more sugars $(14.56 \%)$ were available. The analysis of straw treated in the different layers of the multiple-layer reactor indicated a decrease of the lignin content, when comparing the layers from top (17.5\%) over mid (13.0\%) to bottom (7.2\%). Correspondingly, the amount of available sugars increased from top to bottom (top $8.8 \%$, mid $16.9 \%$, and bottom $28.4 \%$ ). This suggests that the highest treatment efficiency is to be found in the bottom layer, where most ozone was available for lignin degradation.

3.2. Effect of the PAP Treatment on the Methane Yield. In the batch digestion trials, the effect of the PAP treatment on the anaerobic digestibility of wheat straw was tested. The digestion of raw wheat straw resulted in a specific methane yield of $254 \pm 19 \mathrm{~mL} / \mathrm{gVS}$, while all batches with pretreated wheat straw had higher specific methane yields (Table 1). Wheat straw treated in the single layer reactor (SIN) resulted in a yield of $317 \pm 5 \mathrm{~mL} / \mathrm{gVS}$. After treatment in the multiple layer reactor, wheat straw was converted to methane with yields of $311 \pm 10 \mathrm{~mL} / \mathrm{gVS}$ (BOT (10)), $\mathrm{zmbox}$ $301 \pm 0.1 \mathrm{~mL} / \mathrm{gVS}$ (MID), and $286 \pm 7 \mathrm{~mL} / \mathrm{gVS}$ (TOP). These yields indicate little but no substantial difference between the layers with respect to their effect on anaerobic digestibility. This was otherwise suggested by the differences in lignin content and available sugars. Presumably, inhibitory effects of lignin degradation products have balanced out the beneficiary effects of a stronger treatment. However, SIN achieved the highest yield among the tested treatments, while only

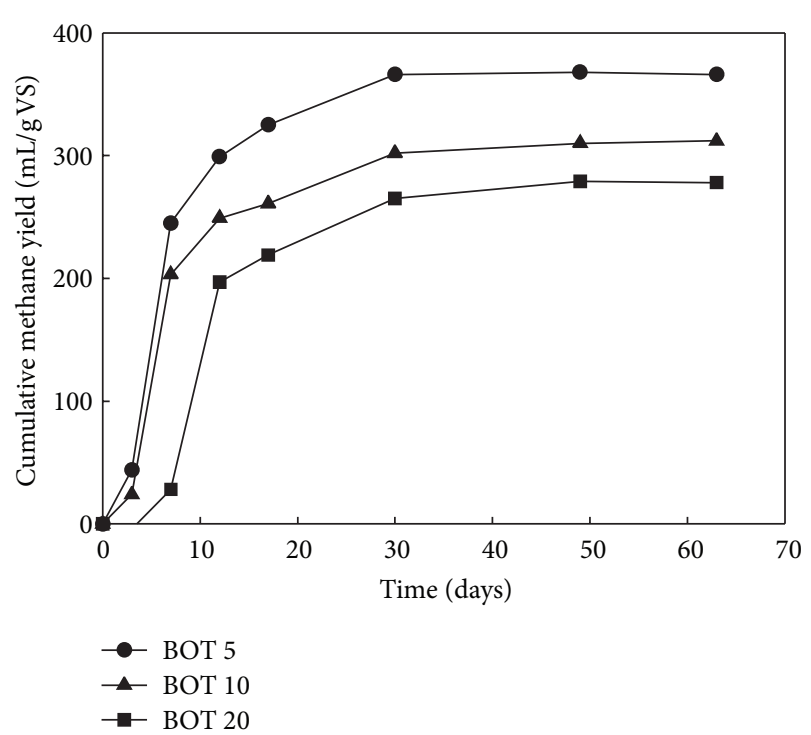

FIGURE 2: Accumulated methane production of bottom layer-treated wheat straw digested at different substrate concentrations.

having a comparatively moderate lignin removal and sugar availability.

3.3. Effect of Substrate Concentration. The highest lignin removal was achieved in the bottom layer. Accordingly, a higher concentration of potentially inhibiting lignin degradation products is expected in BOT, which therefore was tested for inhibition by using different substrate amounts in the batch trial. The previous assumption of adverse effects by lignin derivatives is supported by the methane yields achieved when digesting different substrate concentrations of BOT, indicating inhibition at higher concentrations (Figure 2). BOT20 showed a 7-day lag-phase as well as a lower final methane yield $(278 \pm 9 \mathrm{~mL} / \mathrm{gVS})$ when compared to BOT10 $(312 \pm 10 \mathrm{~mL} / \mathrm{gVS})$. BOT10 did not show a distinct lagphase but resulted in a lower final methane yield than BOT5 $(366 \pm 9 \mathrm{~mL} / \mathrm{gVS})$. The analysis of washing water from plasma pretreated wheat straw [12] revealed the presence of various phenolic compounds, which are known to have a negative effect on methane production $[22,23]$. Phenolic compounds can inhibit enzymatic hydrolysis of cellulose [24] and thereby lower the methane yield from lignocellulosic 


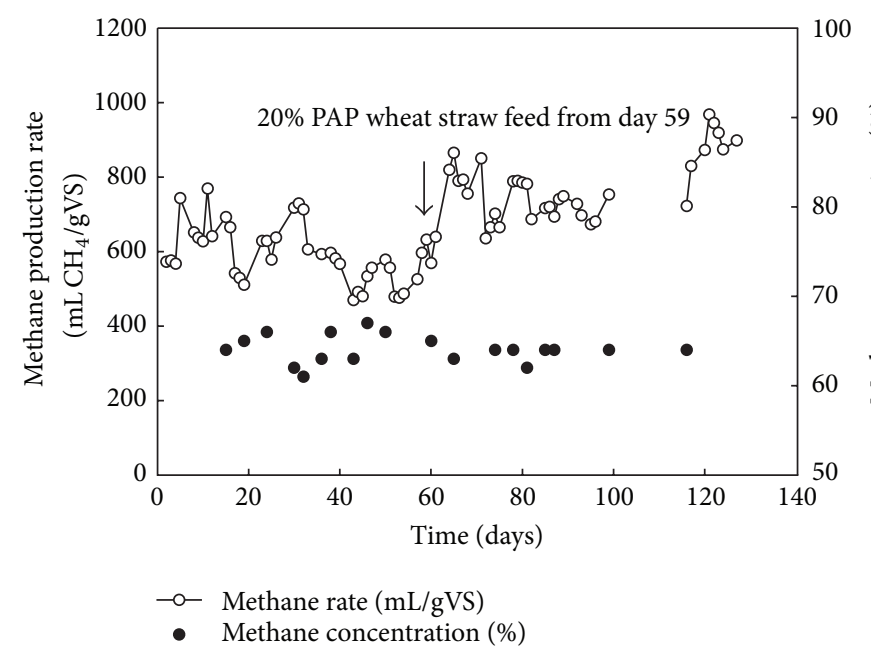

(a)

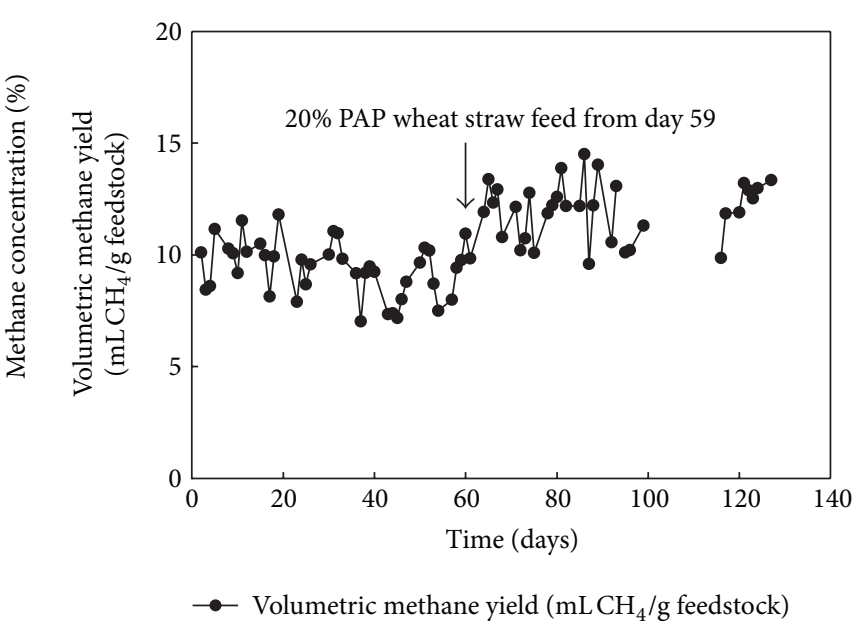

(b)

FIGURE 3: Methane production rate and $\mathrm{CH}_{4}$ concentration in the course of the continuous trial (a). Volumetric methane yield in the course of the continuous trial (b).

substrate as straw. As phenols can be degraded anaerobically $[25,26]$, the lag-phase for BOT20 could have been caused by the initial phenol concentration, which was subsequently lowered due to degradation. However, the differences in the final methane yield indicated the presence of other, nondegradable inhibitors. Furfural and 5-HMF, known inhibitors typically found after, for example, thermal pretreatment of lignocellulosic material [27], were under detection limit after PAP (data not shown). Thus, the inhibiting effect of PAP wheat straw at high substrate concentrations is presumably related to other nonidentified compounds.

Despite potential inhibition, the beneficial effect of the pretreatment on the methane potential of the straw is significant at low substrate concentrations. When compared to raw wheat straw (for which no substrate inhibition was assumed in the present concentration range of from 5 to $20 \mathrm{gVS} / \mathrm{L}$ [28]), the increase in methane potential amounts to $45 \%$ for BOT5.

3.4. Continuous Trials. Adding PAP wheat straw to the manure-feed of the CSTR increased the methane production rate (daily methane production per liter reactor volume) from $593 \pm 79 \mathrm{~mL} \mathrm{~L}^{-1} \mathrm{~d}^{-1}$ (days 0-59) to $761 \pm 94 \mathrm{~mL} \mathrm{~L}^{-1} \mathrm{~d}^{-1}$ (days 60-127) (Figure 3(a)). Data from day 100 to day 115 has been excluded due to a technical failure on day 100, followed by a two-week period for rebalancing the process. The average volumetric methane yield increased from $9.34 \pm$ $1.24 \mathrm{~mL} / \mathrm{g}$ feedstock (manure) to $11.86 \pm 1.35 \mathrm{~mL} / \mathrm{g}$ feedstock (manure and straw) (Figure 3(b)). The yields obtained in the continuous process confirmed the results of the batch trials; the straw was digested with an average yield of $343 \pm 17 \mathrm{~mL} \mathrm{CH}_{4} / \mathrm{gVS}$, corresponding to an increase of $35 \%$ when compared to untreated wheat straw in batch digestion. Adverse effects on the digestions process by the addition of straw have not been observed. The $\mathrm{pH}$ in the reactor remained stable at $7.77 \pm 0.06$ during the entire experiment.
The concentrations of acetate $(13 \pm 1.4 \mathrm{mMol})$ and propionate $(1.8 \pm 0.31 \mathrm{mMol})$ were low and stable, which indicates that the process adapted well to the introduction of the pretreated straw as cosubstrate since propionate fluctuation is a widely used indicator of process stress in anaerobic reactors [29, 30]. The methane concentration showed minor fluctuations during the reference period $(64.1 \pm 1.8 \%)$ and stabilized during codigestion $(63.8 \pm 0.9 \%)$ indicating no effect of the addition of pretreated wheat straw on the biogas composition (Figure 3(a)).

3.5. Energy Considerations. The PAP setup used in this study consumed $160 \mathrm{~g}$ Ozone per hour treatment time and $\mathrm{kg}$ biomass (dry weight), requiring $3.8 \mathrm{MJ}$ for ozone production [13]. The additional methane gained from the pretreatment accounts for of $112 \mathrm{~L} / \mathrm{kg}$ straw, corresponding to an energy gain of $3.8 \mathrm{MJ} / \mathrm{kg}$. Hence, the energy demand for PAP cancels out the energy benefits of the treatment. Considering the early stage of development of PAP and the simple, not optimized ozone feed of the lab-scale setup, we assume that the method has potential for significant improvements which could result in a positive energy budget. Ozone could be fed more efficiently and recycled from the outgas. Further, treatment times could be optimized with respect to lignin degradation and ozone consumption.

3.6. Utilization of Lignin Products. PAP is potentially a particularly suitable technology for the recovery of high value compounds from lignocellulosic biomass; Schultz-Jensen et al. [12] noted that the temporal release pattern of various degradation products (e.g., phenols, benzene, fatty acids, etc.) during the treatment suggests further investigation on more targeted recovery of lignin derived products by PAP. As lignin is the only renewable source of aromatic compounds [31], the utilization of lignin degradation products adds an important aspect to the objective of PAP. Besides facilitating 
microbial access to cellulose and hemicellulose, the recovery of lignin derivatives could contribute to a more complete utilization of biomass which combines biogas production with the extraction of value added chemical products.

3.7. Future Perspective. Technical improvements towards a minimal use of ozone are crucial to make PAP a feasible method for large scale applications. Tests with modified reactor design need to be carried out to evaluate the margins for increasing process efficiency. Broader screening for inhibitory compounds and detailed monitoring of lignin derivate formation patterns would provide the knowledge necessary to specifically adjust PAP parameters for applications like biogas production and/or selective recovery of derivatives. Investigations on the long-term performance of $\mathrm{AD}$ with high concentrations of PAP substrate could give valuable information about adverse effects and microbial adaptation.

\section{Conclusions}

Plasma-assisted pretreatment significantly reduced the lignin content of wheat straw and increased the sugar availability substantially. The methane yield of wheat straw was increased up to $45 \%$ by PAP, suggesting the method to be efficient in facilitating the conversion of lignocellulosic biomass to biogas. PAP of wheat straw in a multiple-layer reactor indicated a better lignin removal and higher methane yields at a higher ozone exposure. Presumably, a higher ozone exposure also leads to an increased formation of inhibitory compounds which counteract the benefits of the lignin removal; batch digestion trials indicated moderate inhibition at high substrate concentrations. However, continuous trials demonstrated that codigestion with $20 \%$ PAP wheat straw and $80 \%$ cattle manure was possible. The pretreated straw was codigested with a specific methane yield of $343 \mathrm{~mL} \mathrm{CH}_{4} / \mathrm{gVS}$. The anaerobic process was stable and no adverse effects were observed during the continuous experiment.

In this lab-scale study, the energy benefit from a higher methane yield was cancelled out by the energy demand for ozone production. Further development and research is necessary to evaluate the applicability of plasma-assisted pretreatment of crop residues prior to anaerobic digestion.

\section{Conflict of Interests}

The authors affirm that this study and all related work were carried out without any conflict of interests.

\section{Acknowledgments}

The authors want to thank Ingelis Larsen, Annette Eva Jensen, and Tomas Fernqvist for technical assistance. This project was supported by the Danish Energy Foundation (EFP07, J. no. 33033-0043) and INBIOM-Innovation Network for Biomass, Denmark.

\section{References}

[1] B. B. Ress, P. P. Calvert, C. A. Pettigrew, and M. A. Barlaz, “Testing anaerobic biodegradability of polymers in a laboratory-scale simulated landfill," Environmental Science and Technology, vol. 32, no. 6, pp. 821-827, 1998.

[2] S. I. Mussatto, M. Fernandes, A. M. F. Milagres, and I. C. Roberto, "Effect of hemicellulose and lignin on enzymatic hydrolysis of cellulose from brewer's spent grain," Enzyme and Microbial Technology, vol. 43, no. 2, pp. 124-129, 2008.

[3] P. Alvira, E. Tomás-Pejó, M. Ballesteros, and M. J. Negro, "Pretreatment technologies for an efficient bioethanol production process based on enzymatic hydrolysis: a review," Bioresource Technology, vol. 101, no. 13, pp. 4851-4861, 2010.

[4] F. Talebnia, D. Karakashev, and I. Angelidaki, "Production of bioethanol from wheat straw: an overview on pretreatment, hydrolysis and fermentation," Bioresource Technology, vol. 101, no. 13, pp. 4744-4753, 2010.

[5] H. Hartmann, I. Angelidaki, and B. K. Ahring, "Increase of anaerobic degradation of particulate organic matter in fullscale biogas plants by mechanical maceration," Water Science and Technology, vol. 41, no. 3, pp. 145-153, 2000.

[6] I. Angelidaki and B. K. Ahring, "Methods for increasing the biogas potential from the recalcitrant organic matter contained in manure," Water Science and Technology, vol. 41, no. 3, pp. 189194, 2000.

[7] Z. Mladenovska, H. Hartmann, T. Kvist, M. Sales-Cruz, R. Gani, and B. K. Ahring, "Thermal pretreatment of the solid fraction of manure: impact on the biogas reactor performance and microbial community," Water Science and Technology, vol. 53, no. 8, pp. 59-67, 2006.

[8] M. Hjorth, K. Gränitz, A. P. S. Adamsen, and H. B. Møller, "Extrusion as a pretreatment to increase biogas production," Bioresource Technology, vol. 102, pp. 4989-4994, 2011.

[9] G. Lissens, A. B. Thomsen, L. De Baere, W. Verstraete, and B. K. Ahring, "Thermal wet oxidation improves anaerobic biodegradability of raw and digested biowaste," Environmental Science and Technology, vol. 38, no. 12, pp. 3418-3424, 2004.

[10] P. F. Vidal and J. Molinier, "Ozonolysis of lignin-improvement of in vitro digestibility of poplar sawdust," Biomass, vol. 16, no. 1, pp. 1-17, 1988.

[11] K. Kratzl, P. Claus, and G. Reichel, "Reactions of lignin and lignin model compounds with ozone," Tappi, vol. 59, no. 11, pp. 86-87, 1976.

[12] N. Schultz-Jensen, Z. Kádár, A. B. Thomsen, H. Bindslev, and F. Leipold, "Plasma-assisted pretreatment of wheat straw for ethanol production," Applied Biochemistry and Biotechnology, vol. 165, pp. 1010-1023, 2011.

[13] N. Schultz-Jensen, F. Leipold, H. Bindslev, and A. B. Thomsen, "Plasma-assisted pretreatment of wheat straw," Applied Biochemistry and Biotechnology, vol. 163, no. 4, pp. 558-572, 2011.

[14] F. Leipold, A. Fateev, Y. Kusano, B. Stenum, and H. Bindslev, "Reduction of NO in the exhaust gas by reaction with $\mathrm{N}$ radicals," Fuel, vol. 85, no. 10-11, pp. 1383-1388, 2006.

[15] F. Leipold, N. Schultz-Jensen, Y. Kusano, H. Bindslev, and T. Jacobsen, "Decontamination of objects in a sealed container by means of atmospheric pressure plasmas," Food Control, vol. 22, no. 8, pp. 1296-1301, 2011.

[16] M. Laroussi and F. Leipold, "Evaluation of the roles of reactive species, heat, and UV radiation in the inactivation of bacterial cells by air plasmas at atmospheric pressure," International Journal of Mass Spectrometry, vol. 233, no. 1-3, pp. 81-86, 2004. 
[17] B. M. Penetrante, J. N. Bardsley, and M. C. Hsiao, "Kinetic analysis of non-thermal plasmas used for pollution control," Japanese Journal of Applied Physics, vol. 36, no. 7, pp. 5007-5017, 1997.

[18] F. Leipold, Y. Kusano, F. Hansen, and T. Jacobsen, "Decontamination of a rotating cutting tool during operation by means of atmospheric pressure plasmas," Food Control, vol. 21, no. 8, pp. 1194-1198, 2010.

[19] A. E. Greenberg, L. S. Clesceri, and A. D. Eaton, Standard Methods For the Examination of Water and Wastewater, American Public Health Association, 18th edition, 1992.

[20] I. Angelidaki, L. Ellegaard, and B. K. Ahring, "Compact automated displacement gas metering system for measurement of low gas rates from laboratory fermentors," Biotechnology and Bioengineering, vol. 39, no. 3, pp. 351-353, 1992.

[21] E. Varga, A. S. Schmidt, K. Réczey, and A. B. Thomsen, "Pretreatment of corn stover using wet oxidation to enhance enzymatic digestibility," Applied Biochemistry and Biotechnology A, vol. 104, no. 1, pp. 37-50, 2003.

[22] F. B. Castro, P. M. Hotten, E. R. Orskov, and M. Rebeller, "Inhibition of rumen microbes by compounds formed in the steam treatment of wheat straw," Bioresource Technology, vol. 50, no. 1, pp. 25-30, 1994.

[23] W. S. Borneman, D. E. Akin, and W. P. VanEseltine, "Effect of phenolic monomers on ruminal bacteria," Applied and Environmental Microbiology, vol. 52, no. 6, pp. 1331-1339, 1986.

[24] E. Ximenes, Y. Kim, N. Mosier, B. Dien, and M. Ladisch, "Deactivation of cellulases by phenols," Enzyme and Microbial Technology, vol. 48, no. 1, pp. 54-60, 2011.

[25] J. E. Hernandez and R. G. J. Edyvean, "Inhibition of biogas production and biodegradability by substituted phenolic compounds in anaerobic sludge," Journal of Hazardous Materials, vol. 160, no. 1, pp. 20-28, 2008.

[26] M. Torry-Smith, P. Sommer, and B. K. Ahring, "Purification of bioethanol effluent in an UASB reactor system with simultaneous biogas formation," Biotechnology and Bioengineering, vol. 84, no. 1, pp. 7-12, 2003.

[27] E. Bruni, A. P. Jensen, and I. Angelidaki, "Steam treatment of digested biofibers for increasing biogas production," Bioresource Technology, vol. 101, no. 19, pp. 7668-7671, 2010.

[28] A. G. Hashimoto, "Effect of inoculum/substrate ratio on methane yield and production rate from straw," Biological Wastes, vol. 28, no. 4, pp. 247-255, 1989.

[29] K. Boe, D. J. Batstone, J. P. Steyer, and I. Angelidaki, "State indicators for monitoring the anaerobic digestion process," Water Research, vol. 44, no. 20, pp. 5973-5980, 2010.

[30] H. B. Nielsen, H. Uellendahl, and B. K. Ahring, "Regulation and optimization of the biogas process: propionate as a key parameter," Biomass and Bioenergy, vol. 31, no. 11-12, pp. $820-$ 830, 2007.

[31] J. E. Holladay, J. F. White, J. J. Bozell, and D. Johnson, “Top valueadded chemicals from biomass; volume II-results of screening for potential candidates from biorefinery lignin," Tech. Rep. PNNL-16983, 2007. 

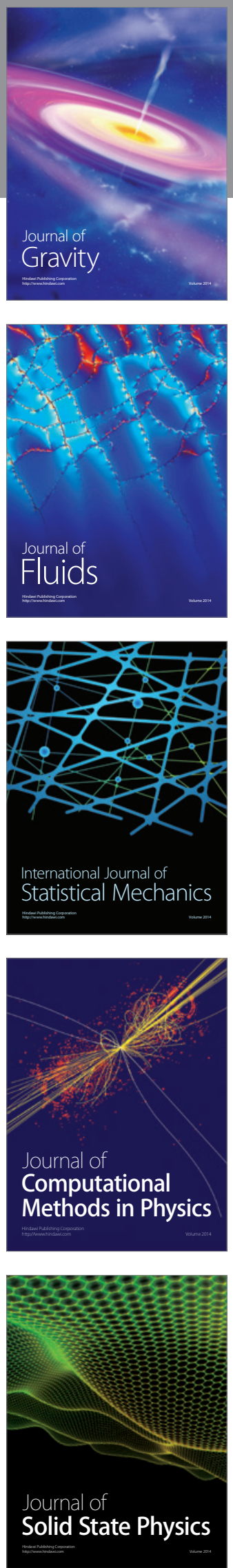

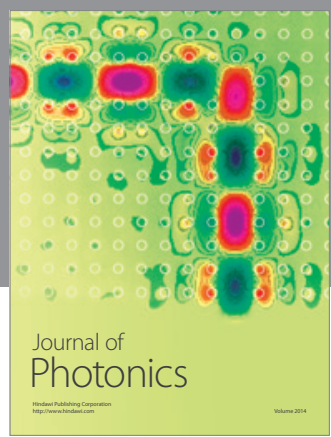

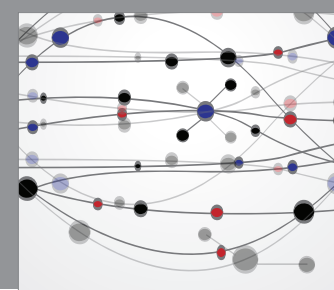

The Scientific World Journal

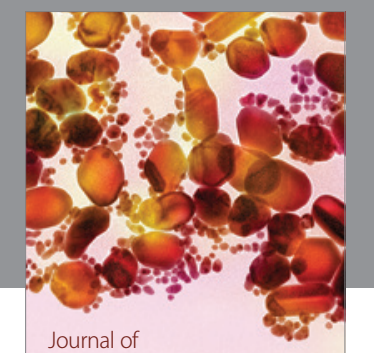

Soft Matter
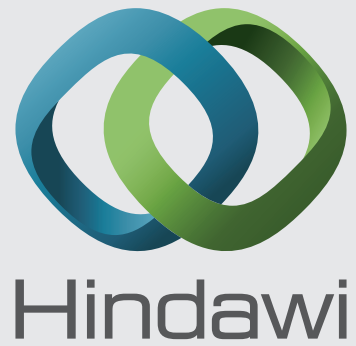

Submit your manuscripts at

http://www.hindawi.com
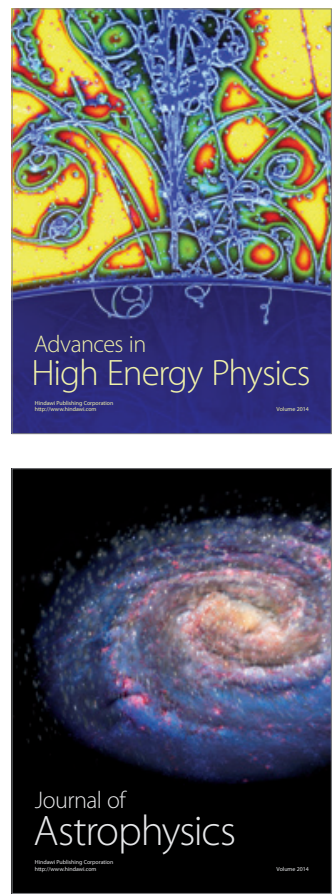
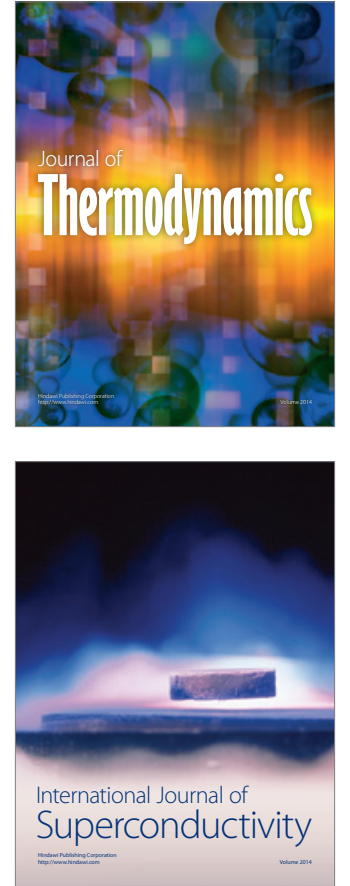
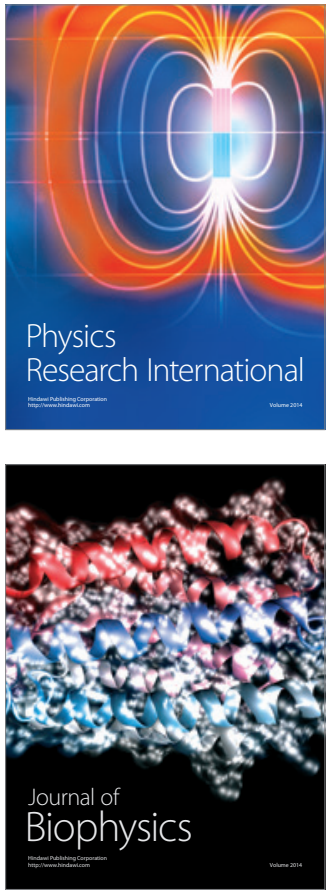
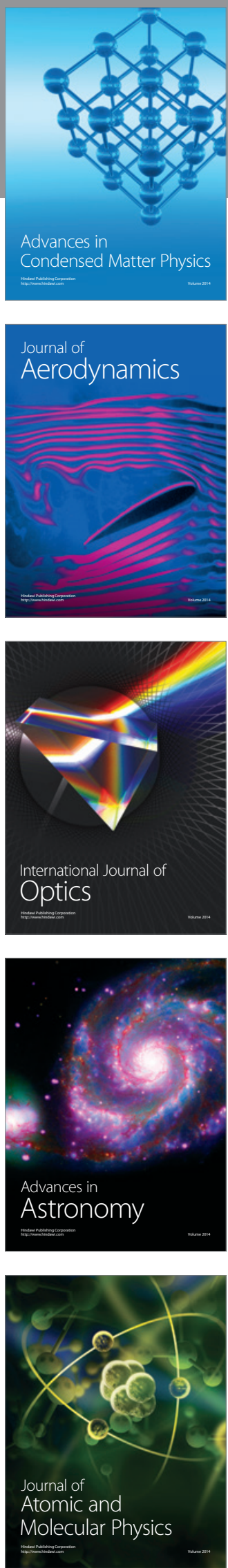